\title{
Molecular transport through primary human small intestinal monolayers by culture on a collagen scaffold with a gradient of chemical cross-linking
}

Jennifer E. Speer ${ }^{1}$, Dulan B. Gunasekara², Yuli Wang ${ }^{1}$, John K. Fallon ${ }^{3}$, Peter J. Attayek², Philip C. Smith', Christopher E. Sims ${ }^{1}$ and Nancy L. Allbritton ${ }^{1,2^{*}}$ (D)

\begin{abstract}
Background: The luminal surface of the small intestine is composed of a monolayer of cells overlying a lamina propria comprised of extracellular matrix (ECM) proteins. The ECM provides a porous substrate critical for nutrient exchange and cellular adhesion. The enterocytes within the epithelial monolayer possess proteins such as transporters, carriers, pumps and channels that participate in the movement of drugs, metabolites, ions and amino acids and whose function can be regulated or altered by the properties of the ECM. Here, we characterized expression and function of proteins involved in transport across the human small intestinal epithelium grown on two different culture platforms. One strategy employs a conventional scaffolding method comprised of a thin ECM film overlaying a porous membrane while the other utilizes a thick ECM hydrogel placed on a porous membrane. The thick hydrogel possesses a gradient of chemical cross-linking along its length to provide a softer substrate than that of the ECM film-coated membrane while maintaining mechanical stability.

Results: The monolayers on both platforms possessed goblet cells and abundant enterocytes and were impermeable to Lucifer yellow and fluorescein-dextran $(70 \mathrm{kD})$ indicating high barrier integrity. Multiple transporter proteins were present in both primary-cell culture formats at levels similar to those present in freshly isolated crypts/villi; however, expression of breast cancer resistance protein (BCRP) and multidrug resistance protein 2 (MRP2) in the monolayers on the conventional scaffold was substantially less than that on the gradient cross-linked scaffold and freshly isolated crypts/villi. Monolayers on the conventional scaffold failed to transport the BCRP substrate prazosin while cells on the gradient cross-linked scaffold successfully transported this drug to better mimic the properties of in vivo small intestine.
\end{abstract}

Conclusions: The results of this comparison highlight the need to create in vitro intestinal transport platforms whose characteristics mimic the in vivo lamina propria in order to accurately recapitulate epithelial function.

Keywords: Intestinal transport, Stiffness, Extracellular matrix, Small intestine

\footnotetext{
* Correspondence: nlallbri@unc.edu

'Department of Chemistry, University of North Carolina, Chapel Hill, NC

27599, USA

${ }^{2}$ Joint Department of Biomedical Engineering, University of North Carolina

and North Carolina State University, Raleigh, NC 27599, USA

Full list of author information is available at the end of the article
}

(c) The Author(s). 2019 Open Access This article is distributed under the terms of the Creative Commons Attribution 4.0 International License (http://creativecommons.org/licenses/by/4.0/), which permits unrestricted use, distribution, and reproduction in any medium, provided you give appropriate credit to the original author(s) and the source, provide a link to the Creative Commons license, and indicate if changes were made. The Creative Commons Public Domain Dedication waiver (http://creativecommons.org/publicdomain/zero/1.0/) applies to the data made available in this article, unless otherwise stated. 


\section{Background}

The luminal surface of the small intestine is composed of a single layer of polarized columnar epithelial cells with the most prevalent cell type being enterocytes, absorptive cells that transport nutrients, salt, metabolites and drugs [1]. The presence of villi lining the intestinal surface greatly increases the absorptive area, while microvilli covering the surface of the enterocytes, known as the brush border, increases the cellular surface area for transport and passive absorption [2, 3]. Proteins expressed by the epithelium facilitate the transport of drugs, metabolites, ions and amino acids [4]. The two major families of drug transporter proteins found in the small intestine are the ATP-binding cassette (ABC) superfamily and the solute carrier (SLC) superfamily, both of which mediate drug and metabolite uptake and export. $\mathrm{ABC}$ transporters harness energy from ATP hydrolysis to actively transport substrates across cellular membranes, whereas SLC transporters are primarily involved in the passive uptake of small molecules into cells [5]. The ABC transporter family includes clinically important proteins such as P-glycoprotein (P-gp), multidrug resistance proteins (MRP1, 2, 3), and breast cancer resistance protein (BCRP) [6]. The SLC transporters participate in both absorption and secretion of anionic and cationic molecules and include proteins such as the organic cation transporter 3 (ОCT3) [7, 8]. $\mathrm{Na}^{+} /$ $\mathrm{K}^{+}$-ATPase and gamma-glutamyl transpeptidase (GGTP) are not part of the two major superfamilies but play important roles in the transport of molecules. The $\mathrm{Na}^{+}$/ $\mathrm{K}^{+}$-ATPase enzyme present on the basal aspect of the epithelial cells actively exports sodium while importing potassium, both against their concentration gradient. The resulting $\mathrm{Na}^{+}$gradient drives a $\mathrm{Na}^{+}$-glucose symporter on the cells' luminal face that imports both $\mathrm{Na}^{+}$and glucose in an efficient manner [4, 9]. GGTP is a transferase in the brush border that catalyzes the transfer of gamma-glutamyl functional groups from glutathione to an acceptor such as a peptide or amino acid to form glutamate, and in the intestine is involved in amino acid absorption $[10,11]$. To study the function of these various proteins, particularly for drug and nutrient transport, development of a primary, human intestinal epithelial monolayer system providing access to the luminal and basal aspects of the epithelium is a necessary tool.

To perform transport studies, typically human cancer lines, such as Caco-2, are used as a model system as they are inexpensive, easy to culture, are readily available, and can be differentiated to an enterocyte-like cell. While tumor model systems have played a valuable role in drug discovery, these cells often fail to predict in vivo behavior due to inappropriate expression levels or mutations of transporters and enzymes in comparison with the normal intestine [12]. Animal models are also often used to predict intestinal absorption, but are technically difficult, expensive, and face increasing ethical challenges [13]. These non-human model systems may also display levels and physical locations of proteins distinct from that of humans, resulting in inaccurate clinical predictions [14]. Human intestine explant cultures have been used for drug absorption studies, but the short survival times of these systems ex vivo makes their routine use impractical for intestinal transport studies [15]. Enteroids derived from mouse and human intestinal stem cells recapitulate many features of small intestine epithelial cell function. However, enteroids are closed spherical structures embedded within a hydrogel with lumen not easily accessed, thus making the system challenging for use in transport studies [13].

Differentiated intestinal epithelial monolayers derived from primary intestinal stem cells demonstrate much of the in vivo cell architecture and function including proper luminal-to-basal cell polarity, the presence of tight junctions, and all differentiated cell types of the in vivo epithelium [15-18]. When cultured on a porous membrane, such as a Transwell ${ }^{\mathrm{Tm}}$, these monolayer systems provide ready access to the luminal and basal reservoirs bathing the tissue and enable fluid sampling for influx and efflux studies. To address the need for improved systems for drug assays, a variety of different formats to form epithelial monolayers have been described [16-20]. These systems are most distinguished by the culture surface used, often a thin coating of extracellular matrix (ECM) on a polymer surface such as polycarbonate, polystyrene, or polydimethylsiloxane (PDMS). While these systems demonstrate gene expression at the mRNA level of known transporters, these non-natural polymer culture surfaces can have a profound impact of transporter activity since the underlying stiff surfaces do not replicate most features of the lamina propria [21, 22]. Thick collagen scaffolds mimicking critical features of the lamina propria, such as its stiffness, have been shown to support both human and mouse primary intestinal monolayers for short-term assay or long-term culture [23-25]. A recently described scaffolding utilizes a gradient of chemical cross-linking across a thick collagen hydrogel so that the luminal collagen surface in contact with cells mimics the stiffness of in vivo intestine while the more cross-linked or rigid basal surface prevents gross hydrogel deformation by the cells [25]. However, the cells on this newer physiologic scaffold have not been characterized with regard to their transporter protein expression and function.

The stiffness of the matrix, such as the lamina propria, underlying cells in vivo and in culture has long been known to have a profound influence on cellular physiology, impacting properties as diverse as proliferation, differentiation, protein expression and signal transduction among others [26-28]. For example, ECM 
stiffness is known to influence stem-cell fate through regulated mechano-sensing pathways [29-31]. Despite a growing interest, limited studies of the interplay of stiffness and stem cell self-renewal, cellular differentiation and cell function have been performed in intestinal epithelium. Organoid culture systems have shown optimal intestinal cell growth in stiff matrices and optimal differentiation in soft matrices, yet growth on a planar substrate has shown opposite behavior [23, 25, 32]. The effects of collagen/ECM stiffness on transporters such as BCRP and MRP2 has been studied in cancer cell models $[14,33,34]$, but there is little reported on how matrix stiffness affects protein expression in primary intestinal cell systems. Given the growing importance of model primary-cell culture systems to understand intestinal physiology and drug interactions, there is clear need to understand the matrix or scaffold properties that yield the most in vivo-like drug transport behavior.

In this work, we characterize a conventional scaffold system and a new gradient cross-linked scaffold method for the measurement of drug transport in primary, human small intestinal epithelium [24, 25, 35-39]. Collagen was used as a substrate in both systems since it is the most abundant ECM in the intestine [21]; however, the two systems possessed a scaffold thickness many orders of magnitude different. Stem cells obtained from human small intestine were cultured on a conventional scaffold consisting of a thin collagen film over a porous membrane or on a newly developed scaffold comprised of a thick collagen layer possessing a gradient of chemical cross-linking. The presence of proliferative and differentiated cell lineages was evaluated. The ability of cells to form intercellular tight junctions was evaluated using immunohistochemical staining, and monolayer integrity was assessed by transepithelial electrical resistance (TEER) and permeability. Quantification of specific transporter protein expression was performed by quantitative targeted absolute proteomics (QTAP) by selected reaction monitoring (SRM) nanobore liquid chromatography-tandem mass spectrometry (nanoLC-MS/MS). Lastly, the movement of drugs across the monolayers by both transcellular and paracellular transport was evaluated to assess the platforms' utility for pharmacological assays.

\section{Results and discussion}

Characterization of confluent small intestine monolayers on the conventional and gradient cross-linked scaffolds

While the two, intestinal-cell, culture systems possess a number of technical distinctions, a dominate difference is the very different surface stiffness presented to the cells (Fig. 1a, Additional file 1: Table S1). The gradient cross-linked scaffold (1.2 mm thick) possessed a stiffness of $230 \pm 140 \mathrm{~Pa}$, closely resembling in vivo intestinal stiffness $(640 \pm 340 \mathrm{~Pa})$ [40]. In contrast, the conventional scaffold employing a thin $(<900 \mathrm{~nm})$ film of collagen exhibited a stiffness $(1.50 \mathrm{MPa} \pm 0.27 \mathrm{MPa})$ more than 2000 -fold greater than that of the gradient-linked scaffold or in vivo intestine and close to that of the porous membrane alone [41, 42]. Cells were initially plated on both surfaces in expansion medium (EM), a medium rich in growth factors (Wnt-3A, R-spondin 3, and noggin) to promote stem cell proliferation and enable formation of a visually confluent monolayer (Fig. 1b, Additional file 1: Figure S1). Since transport of nutrients and drugs is accomplished predominantly by the fully differentiated enterocytes of the intestinal epithelium, differentiation medium (DM), a medium lacking growth factors, was used to replace EM in order to cause the monolayer to fully differentiate. To assess differentiation before and after media exchange, the cells were stained for Muc2 (goblet cells) and alkaline phosphatase (ALP, enterocytes). After 5 days in DM, both Muc2 and ALP staining were significantly greater for both the conventional scaffold and gradient cross-linked scaffold systems compared to cellular monolayers in EM at day 5 (Fig. 1c, Additional file 1: Figure S1). The Muc2 and ALP area coverage on the gradient cross-linked scaffold was not significantly different from that on the conventional scaffold. In vivo large numbers of microvilli cover the surface of enterocytes [43]. By SEM, both monolayer systems demonstrated a dense layer of microvilli on the luminal cell surface with a density of $3.8 \pm 0.7 \times 10^{5}$ and $2.6 \pm 0.3 \times 10^{5} \mathrm{microvilli} / \mathrm{cm}^{2}(n=3)$ on the gradient cross-linked scaffold and conventional scaffold, respectively (Fig. 2a). These values were not significantly different $(p=0.08)$. These findings demonstrate that both monolayer systems had comparable microvillus density to that found in vivo of $4.4 \pm 5.0 \times 10^{5}$ microvilli/ $\mathrm{cm}^{2}$ [44-46]. Actin, a protein expressed at high concentration within microvilli [47], was localized to the luminal cell surface of the monolayers on both culture platforms (Fig. 2b). In contrast, integrin- $\beta 4$, which functions in the formation of ECM contacts [26, 47], was localized to the basal region of the cells on both culture platforms (Fig. 2b). These data suggest that both cell monolayer formats possessed large numbers of enterocytes with appropriate luminal-to-basal polarity supporting their suitability for transport assays.

To function effectively for transport assays, cells within the intestinal epithelial monolayer must form high-resistance contacts to prevent leakage between luminal and basal reservoirs $[21,48]$. In vivo this is accomplished by formation of intercellular tight junctions containing proteins such as $\mathrm{ZO}-1$ and cell-cell adhesion proteins, such as $\beta$-catenin [49]. Both $\beta$-catenin and $\mathrm{ZO}-1$ were readily visualized at the interface between cells on both platforms suggesting that both culture formats might be competent to form monolayers impermeable to small molecules (Fig. 2c, d). 


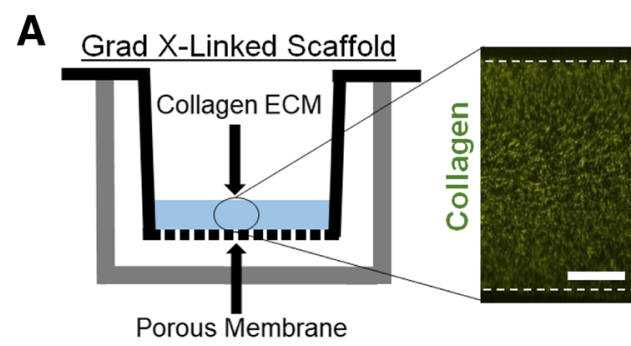

B
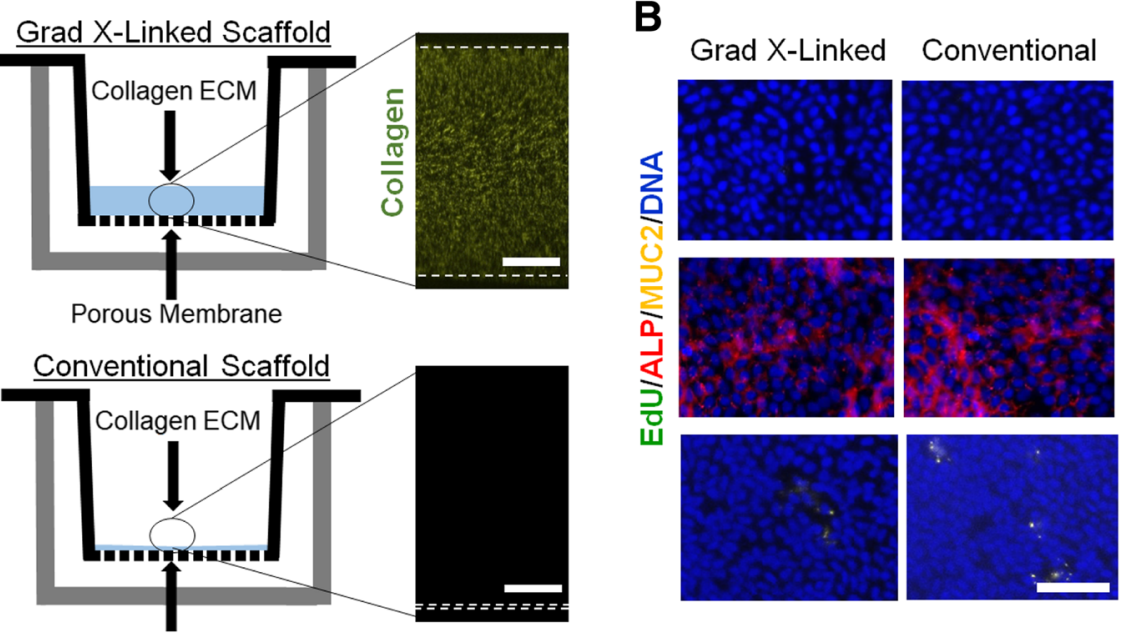

Porous Membrane
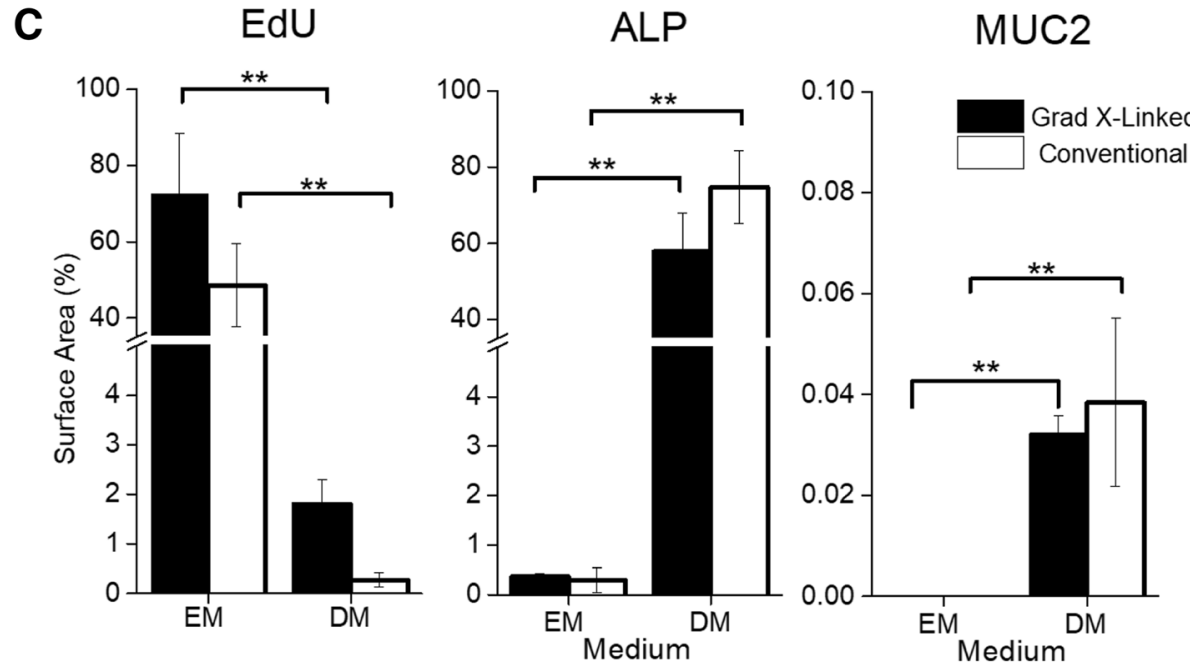

Fig. 1 Evaluation of human, small intestinal monolayer systems. a Schematic and fluorescence side images of the gradient cross-linked scaffold (top) and conventional scaffold overlaying a porous membrane (bottom). Scale bar $=300 \mu \mathrm{m}$. b Fluorescence images of the monolayers at day 10 stained for EdU (green), ALP (red), Muc2 (yellow), and nuclei (blue). Scale bar $=100 \mu \mathrm{m}$. c Quantification of Edu, ALP, and Muc2 on day 5 and day 10 of culture as a percentage of the Hoechst 33342 (nuclei stain) positive area ( $n=3$ ). Edu, ALP, and Muc2 expression was not statistically different between the two monolayer systems in EM or DM

\section{Barrier function and monolayer integrity}

The ability of the monolayer to act as a barrier to the movement of ions, small and larger molecules was evaluated by measuring TEER over a period of 18 days. Monolayers differentiated on the gradient cross-linked scaffold possessed a maximal TEER of $120 \pm 30 \Omega \mathrm{cm}^{2}$ $(n=3)$ at day 11 in culture. In contrast, the TEER for the monolayers on the conventional scaffold achieved a significantly greater value of $760 \pm 20 \Omega \mathrm{cm}^{2}(n=3)$ at day $12(p<0.001$, Fig. 3a). The TEER value for Caco- 2 cells has been reported as $250-4000 \Omega \mathrm{cm}^{2}$ while the in vivo intestine has a reported TEER value of $50-100 \Omega \mathrm{cm}^{2}$ $[4,50]$. Thus, the TEER for the gradient cross-linked scaffold system is more representative of that found in vivo suggesting that the low-stiffness, gradient cross-linked scaffold may provide an in vitro ECM platform more similar to that found in vivo than that produced on stiff surfaces.

While TEER is an important metric for membrane integrity, its value can vary considerably across different regions of the intestine based on that region's ion transport functions, and is most reflective of ion permeability rather than that of large molecules such as drugs [48, 51]. For this reason the ability to block diffusion of non-transported molecules such as Lucifer yellow (LY) or fluorescent dextrans is often used to assess the barrier function of the intestinal epithelium [25, 51]. Both LY and fluorescein-dextran $(70 \mathrm{kDa})$ were added to the luminal reservoir (top) and their movement into the basal reservoir (bottom) measured after $3 \mathrm{~h}$. The permeability of LY and fluorescein dextran through confluent, 


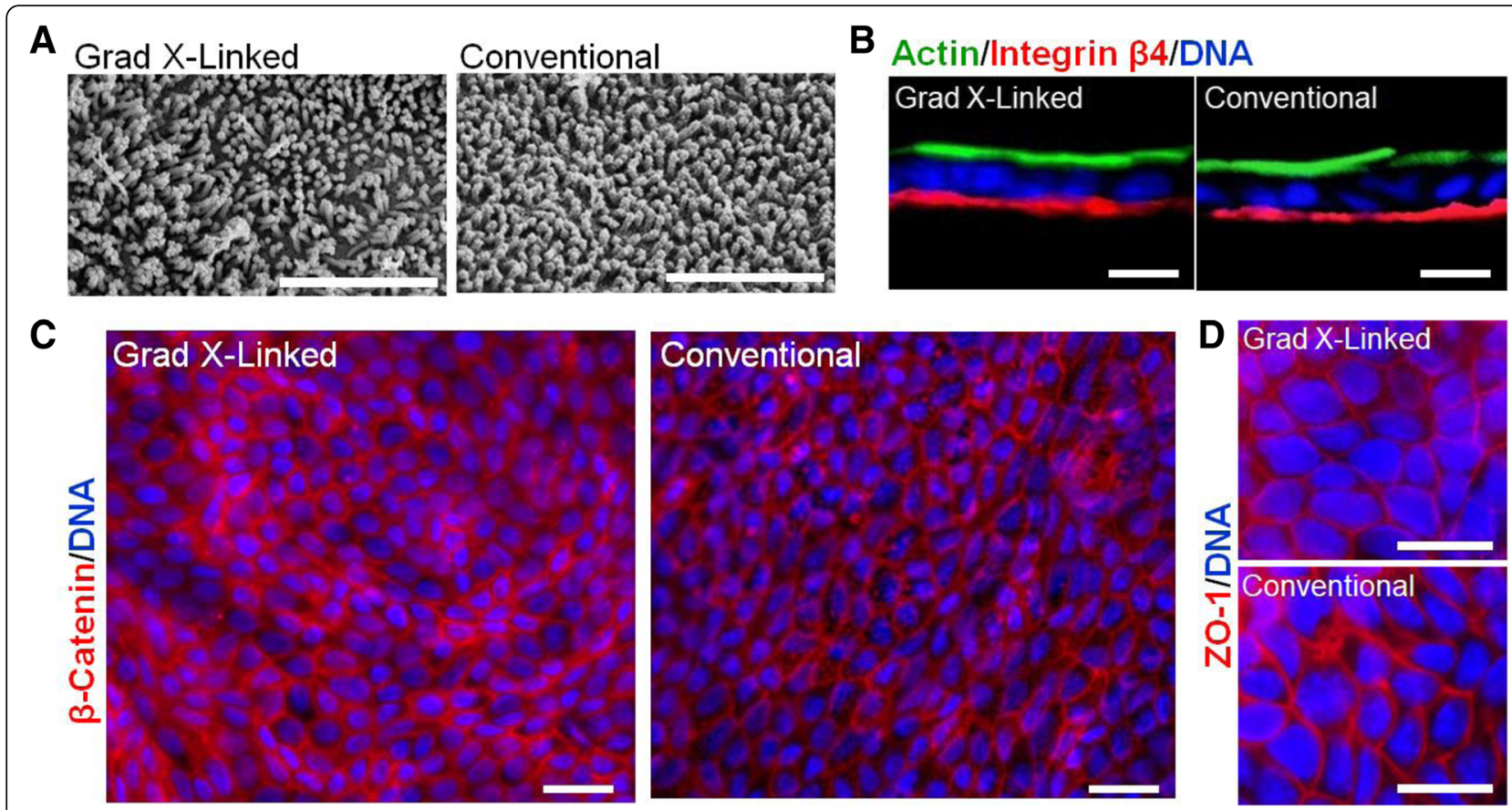

Fig. 2 Characterization of confluent monolayer cultures. a Electron microscopy images of the monolayer surfaces covered with microvilli at day 10. Scale Bar $=4 \mu \mathrm{m}$. b A cross-section of the monolayers stained for F-actin (green) and integrin $\beta 4$ (red). Scale bar $=10 \mu \mathrm{m}$. c Fluorescence images of the monolayers at day 10 stained with a cell adhesion protein $\beta$-Catenin (red) and Hoechst 33342 (nuclei). Scale bar $=10 \mu \mathrm{m}$. $\mathbf{d}$ Monolayer staining of a tight junction protein, ZO-1 (red), and Hoechst 33342 (nuclei, blue). Scale bar = $10 \mu \mathrm{m}$

differentiated monolayers of cells cultured on the gradient cross-linked scaffold and conventional scaffold was low and not significantly different $(n=3)$ (Fig. 3b,c). Previous reports of $\mathrm{LY}$ and fluorescein-dextran $(70 \mathrm{kDA})$ permeability for Caco-2 cells are $<1 \times 10^{-6} \mathrm{~cm} \mathrm{~s}^{-1}$ and $(3-7) \times 10^{-7} \mathrm{~cm} \mathrm{~s}^{-1}$, respectively $[52,53]$. Thus, the two different monolayer systems possessed similar barrier function as that posed by Caco-2 cells. In general for a monolayer to be suitable for transport studies, the monolayer permeability to these non-transported molecules should be $<1 \times 10^{-6} \mathrm{~cm} \mathrm{~s}^{-1}$ [54]. These data suggest that both monolayer culture systems exhibit high barrier integrity.

\section{Measurement of intestinal proteins involved in transport}

Absolute quantitative proteomics via SRM nanoLC/ MS-MS was used to assess the presence of proteins known to participate in the movement of drugs, metabolites, ions and amino acids across the intestinal surface as these are expected to be present in a functional intestinal epithelium [7, 55]. Protein expression levels of monolayers cultured on the conventional scaffold or gradient cross-linked scaffold were measured on day 10 and compared to that of freshly isolated crypts/villi (Table 1, Additional file 1: Figure S2). $\mathrm{Na}^{+} / \mathrm{K}^{+}$-ATPase and GGTP in both monolayer culture systems were expressed at levels similar to that in fresh tissue (Table 1, Additional file 1: Figure S2). P-gp and OCT3 expression on the two systems were also similar to that found in fresh intestinal epithelium (Table 1, Additional file 1: Figure S2). In contrast, BCRP and MRP2 were expressed at comparable levels in the monolayers on the gradient cross-linked scaffold relative to that found in fresh crypts/villi, but at much greater levels than that of the monolayers on the conventional scaffold (Table 1, Additional file 1: Figure S2). The equivalent substrate stiffness compared to in vivo intestine of the gradient cross-linked scaffold and the similar protein expression of BCRP and MRP2 in relation to the fresh crypts/villi tissue suggest that this scaffold may be a more suitable model system for assay of some transporters.

\section{Functional assays}

To evaluate protein function, clinically relevant substrates known to be carried by three different mechanisms were assessed: atenolol (paracellular transport), propranolol (transcellular transport), and digoxin and prazosin (efflux transcellular transport). Atenolol and propranolol are antihypertensive drugs that inhibit the $\beta$-adrenergic receptor and are frequently used as model drugs for assessment of hydrophilic (atenolol) and lipophilic (propranolol) drug uptake [56]. Atenolol uptake is thought to occur passively across the intestinal epithelium between the cells, i.e. through an intercellular 


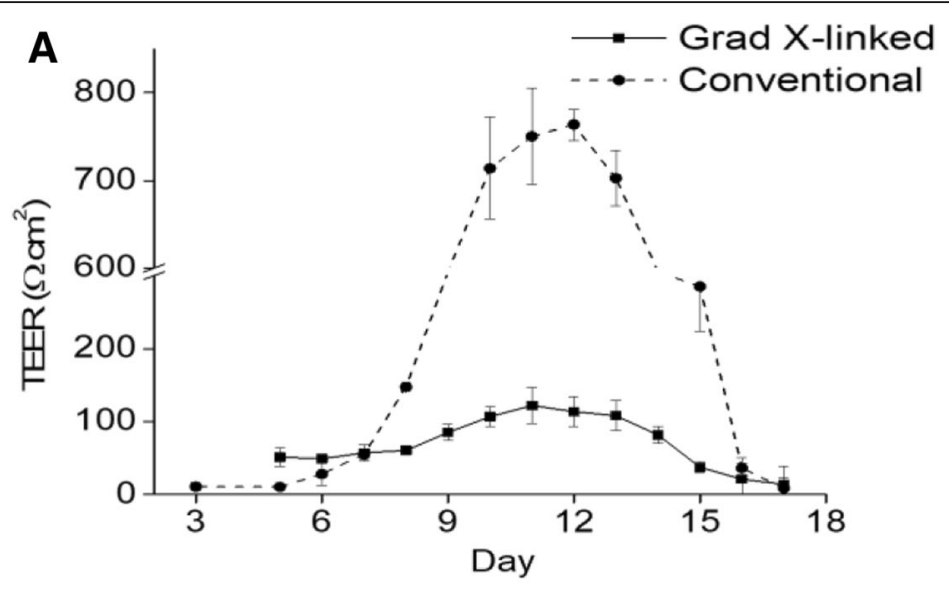

B Lucifer Yellow Permeability
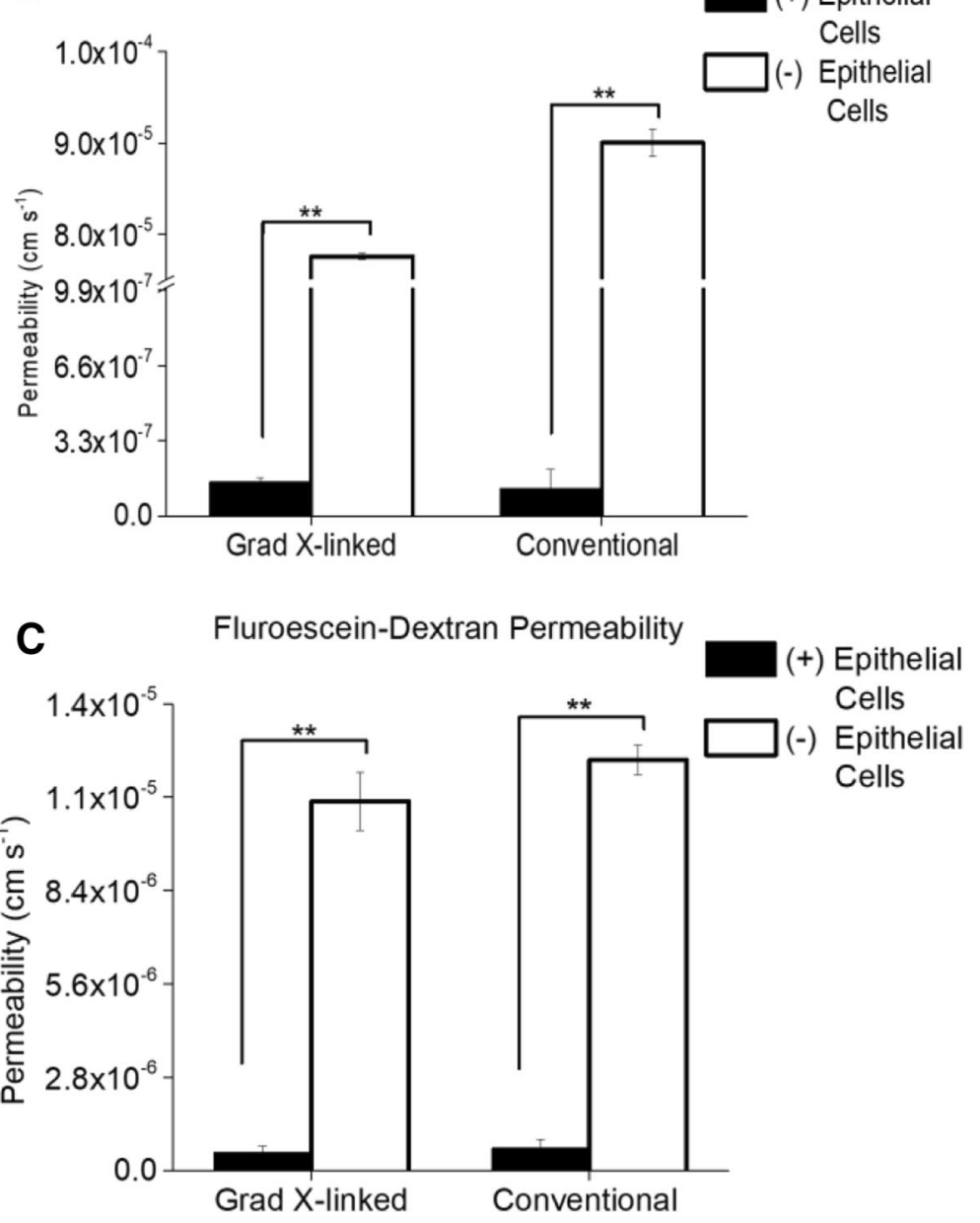

Fig. 3 Evaluation of barrier function and monolayer integrity. a TEER measurements over 18 days in both monolayer culture systems ( $n=3)$. $\mathbf{b} L Y$ permeability values $(n=3)$ and $\mathbf{c})$ fluorescein-dextran permeability values $(n=3)$ through the monolayers on the gradient cross-linked scaffold and conventional scaffold compared to the permeability of LY and fluorescein-dextran of the gradient cross-linked scaffold in the absence of cells $(n=3)$ and conventional scaffold in the absence of cells $(n=3)$ on day 10 of culture. The LY and fluorescein-dextran permeability values through the gradient cross-linked scaffold and conventional scaffold in the absence of cells were not statistically different 
Table 1 Protein expression of selected transporters in both monolayer culture systems measured at day 10 of culture and in fresh crypts/villi. Concentrations (C) are reported in pmol/mg membrane fraction protein; C $>5(++++) ; 5>C>3(+++) ; 3>C>0.5(++)$; $0.5>C(+)$

\begin{tabular}{llll}
\hline Protein & Grad X-linked Scaffold & Conventional Scaffold & Fresh Crypts/ Villi \\
\hline P-gp & ++++ & ++++ & ++++ \\
BCRP & ++++ & + & ++++ \\
MRP1 & + & + & + \\
MRP2 & +++ & ++ & +++ \\
MRP3 & ++ & ++ & ++ \\
OCT3 & ++ & ++ & ++ \\
Na K ATPase & ++++ & ++++ & ++++ \\
GGTP & ++++ & ++++ & ++++ \\
\hline
\end{tabular}

pathway [57]. In contrast, propranolol is thought to move by a transcellular pathway i.e. passing through cell membranes and crossing the cytoplasm [16]. In vitro studies have shown that propranolol can be actively exported as a substrate for P-gp, but the full mechanism is still unknown [58]. Atenolol and propranolol were added to the luminal compartment and samples were collected from the basal reservoir after $3 \mathrm{~h}$ (Fig. 4a). LY served as a control for monolayer barrier integrity. LY permeability was always less than $1 \times 10^{-6} \mathrm{~cm} \mathrm{~s}^{-1}$ in these experiments. The permeability of atenolol through the monolayer on the conventional scaffold was not significantly different from that on the gradient cross-linked scaffold (Fig. 4b, $n=3$ ). The atenolol permeability for both monolayers was similar to that previously reported for Caco-2 cells of $[2-10] \times 10^{-7} \mathrm{~cm} \mathrm{~s}^{-1}$, but substantially different from that estimated from in vivo studies $\left(100-180 \times 10^{-7} \mathrm{~cm} \mathrm{~s}^{-1}\right)$ [59-61]. The permeabilities of propranolol through the monolayer on the gradient cross-linked scaffold and conventional scaffold were not statistically different (Fig. 4b), were comparable to that of Caco-2 cells [4-25] $\times 10^{-6} \mathrm{~cm} \mathrm{~s}^{-1}$, and equivalent to that measured in vivo $\left(5-7 \times 10^{-5} \mathrm{~cm} \mathrm{~s}^{-1}\right)$ [5963]. For the transport of these two drugs, the gradient cross-linked scaffold and conventional scaffold performed in a similar manner, although atenolol uptake was less than that reported for atenolol in vivo $[60,61]$.

To evaluate drug efflux and directional transport, the permeability of digoxin, a P-gp substrate, and prazosin, a BCRP substrate, was added to either the basal or luminal compartments of the two cell culture formats followed by assay of the drug in the opposite reservoir (Fig. 4a). Digoxin, a $\mathrm{Na}+/ \mathrm{K}+$-ATPase inhibitor, is used in the treatment of heart disease, and prazosin, an $\alpha$-1-adrenergic receptor antagonist, is used to treat hypertension $[64,65]$. The permeability of digoxin from the basal to the luminal monolayer side of the gradient cross-linked scaffold $(n=3)$ and conventional scaffold $(n=3)$ was not statistically different (Fig. 4c) and was similar to that reported previously in primary human small intestinal epithelial cells [5-10] $\times 10^{-6} \mathrm{~cm} \mathrm{~s}^{-1}$ [16]. Digoxin had greater permeability in the basal to luminal direction in both the gradient cross-linked and the conventional scaffold with efflux ratio of 2.7 and $2.3(n=3)$, respectively. In the presence of P-gp inhibitor zosuquidar, the efflux ratio of digoxin reduced to $1.4(n=3)$ in both monolayer systems. The permeability of prazosin from the basal to the luminal monolayer side of the gradient cross-linked scaffold $(n=3)$ when cultured on the gradient cross-linked scaffold was comparable to that of previous reports for Caco-2 cell monolayers $\left(3-5 \times 10^{-6} \mathrm{~cm} \mathrm{~s}^{-1}\right)$ [66]. Prazosin moved preferentially from the basal to luminal monolayer side with an efflux ratio of 6.5 on the gradient cross-linked scaffold and was readily blocked by a BCRP inhibitor (Ko143) decreasing the efflux ratio to 1.7. The permeability of prazosin through the monolayer on the conventional scaffold from basal to luminal compartments was below the limits of detection of the assay system (1.2 \pm $\left.0.9 \times 10^{-9} \mathrm{~cm} \mathrm{~s}^{-1}\right)(n=3)$, while the permeability of prazosin through the monolayer on the conventional scaffold from luminal to basal compartments was $2.35 \times 10^{-8}$ (Fig. 4d), demonstrating that efflux transport did not occur. This finding was likely due to the very low level of $\mathrm{BRCP}$ protein expressed in the monolayers on the conventional scaffold relative to that of fresh tissue or the monolayers on the gradient cross-linked scaffold. These data suggest that developing in vitro systems that incorporate features most reflective of the in vivo ECM is important in order to accurately mimic in vivo intestinal epithelial transport.

\section{Conclusions}

Confluent monolayers of human small intestinal epithelial cells were formed using two culture formats: a thick gradient cross-linked collagen scaffold or a more conventional format with a thin film of collagen. While the two systems incorporated a number of differences, the most prominent was the $>1000$-fold difference in 
A

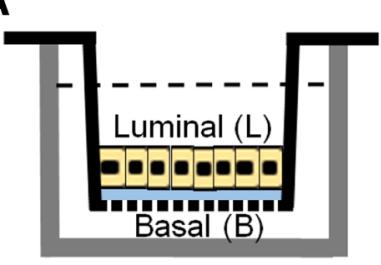

\begin{tabular}{|c|c|c|}
\hline & L to B & B to $\mathbf{L}$ \\
\hline $\begin{array}{c}\text { Luminal } \\
\text { Reservoir }\end{array}$ & $\begin{array}{c}\text { Drug }+ \text { LY } \\
\text { Addition }\end{array}$ & $\begin{array}{c}\text { Sample } \\
\text { Collection }\end{array}$ \\
\hline $\begin{array}{c}\text { Basal } \\
\text { Reservoir }\end{array}$ & $\begin{array}{c}\text { Sample } \\
\text { Collection }\end{array}$ & $\begin{array}{c}\text { Drug + LY } \\
\text { Addition }\end{array}$ \\
\hline
\end{tabular}

B
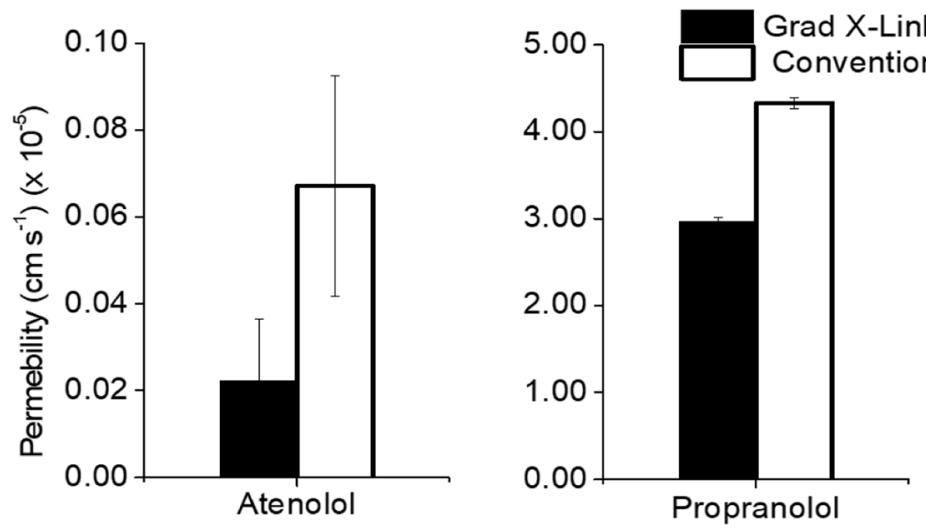

C

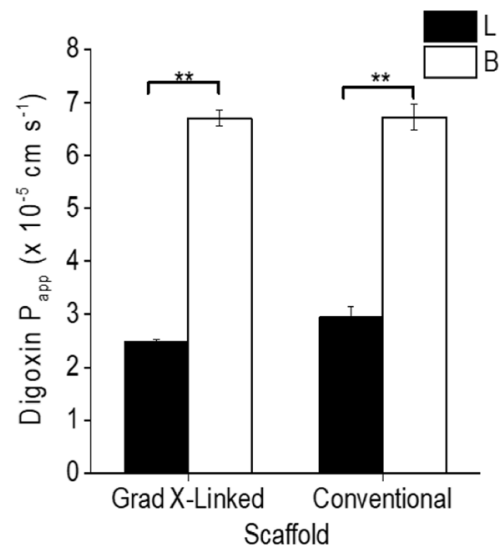

$L$ to $B$ $B$ to $L$
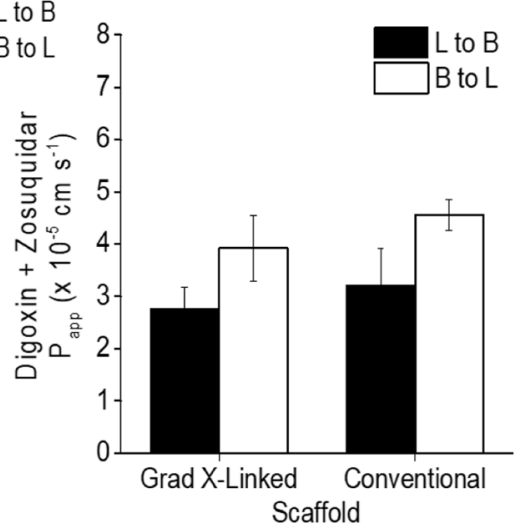

D
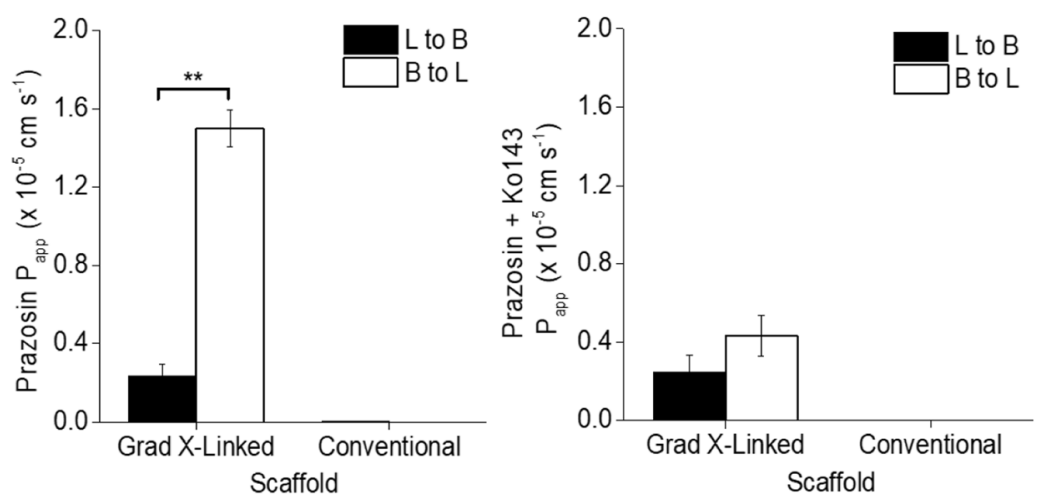

Fig. 4 (See legend on next page.) 
(See figure on previous page.)

Fig. 4 Evaluating compound transport across the monolayer platforms. a Experimental design of luminal to basolateral and basolateral to luminal transport assays. b Permeability values of the monolayer on the culture systems to atenolol (paracellular transported drug, low permeability molecule, $n=3$ ) and propranolol (passive transcellular transported drug, high permeability molecule, $n=3$ ). c Permeability of digoxin in the basal to luminal or luminal to basal direction in the two culture formats without (left panel) and with (right panel) the P-gp inhibitor zosuquidar ( $n=3$ ). The inhibition data was not significantly different for the four data points. $\mathbf{d}$ Permeability of prazosin in the basal to luminal or luminal to basal direction in the two culture formats without (left panel) and with (right panel) the BCRP inhibitor Ko143 $(n=3)$. The inhibition data was not significantly different for the for the two transport directions on each scaffold

scaffold stiffness (Additional file 1: Table S1). The height of the medium above the monolayer in the two culture systems was comparable $(9 \mathrm{~mm}$ gradient cross-linked vs $10 \mathrm{~mm}$ conventional) and COMSOL modeling suggested similar $\mathrm{O}_{2}$ saturation in the two systems (Additional file 1: Figure S3). COMSOL modeling also suggested that access of nutrients to the cells from the luminal and basal reservoirs was indistinguishable for the two culture formats so that the different pore densities in porous membranes was unlikely to impact cell behavior. Finally, the collagen layer/coatings most likely masked any surface chemical differences between the porous membranes of the two culture formats. Despite the vast difference in surface stiffness, the cells on the two culture formats were remarkably similar except in their transport properties. Both formats displayed alkaline phosphatase activity and possessed mucin 2, indicating the presence of enterocytes and goblet cells, respectively. Neither LY nor fluorescein-dextran permeated the cell monolayers suggesting that both monolayer systems yield tissue with high barrier integrity. Additionally, TEER values of both monolayers were equivalent to or higher than that of in vivo intestine suggesting that ions did not readily cross the confluent monolayers. Measurement of protein expression in cells cultured on the gradient cross-linked scaffold and conventional scaffold demonstrated the presence of multiple transporter proteins at levels similar to those present in freshly isolated crypts/villi. A notable exception to these similarities was the diminished expression of the BCRP and MRP2 proteins in the cells on the conventional scaffold compared to that in cells cultured on the gradient cross-linked scaffold and crypts/villi of the small intestine. The monolayer on the conventional scaffold failed to transport the BCRP substrate prazosin from the basal to the luminal compartments although prazosin was transported by the monolayers on the gradient cross-linked scaffold. Given that MRP2 protein expression was low in the cells on the conventional scaffold, it is likely that MRP2 substrates would not be transported by these cells but would be by cells on the gradient cross-linked scaffold since those monolayers possessed similar MRP2 expression to that of the in vivo intestine. Based on the comparable levels of P-gp expression, it was perhaps not surprising that the P-gp substrate digoxin was directionally transported by cells on both culture systems. While we can not rule out alternative mechanisms, the most likely source of the drug transport differences between the two cell monolayers is the scaffolding stiffness. It has been shown that ECM stiffness sensed by the cell are propagated, amplified, and transduced into signaling cascades to lead to transient or sustained cellular responses, ultimately affecting protein expression and amplification and potentially transporter behavior [67]. This is likely the case for a subset of transporter proteins in the intestinal epithelium. This work highlights the importance of developing in vitro scaffold systems for the intestine to recapitulate lamina propria properties as close as possible to yield intestinal models displaying the greatest repertoire of physiologic properties.

\section{Methods \\ Materials}

Rat tail type I collagen, Transwell ${ }^{\text {Tw }}$ inserts, 12-well polystyrene tissue culture dishes, and 12-well polycarbonate filters were purchased from Corning (Corning, NY). Human collagen (type I) was obtained from Advanced Biomatrix (Carlsbad, CA). Collagenase (type IV) was from Worthington Biochemicals (Lakewood, NJ). Gastrin was obtained from Anaspec (Freemont, CA). $\mathrm{N}$-acetyl cysteine was from MP Biomedicals (Santa Ana, CA). Murine EGF was obtained from Peprotech (Rock Hill, NJ). Primocin was purchased from InvivoGen (San Diego, CA). SB202190 was obtained from Selleckchem (Houston, TX). Nicotinamide, A83-01, fluorescein-dextran (70 $\mathrm{kDa}$ ), atenolol, metoprolol, propranolol, prazosin, doxazosin, digoxin, zosuquidar, and digitoxin were acquired from Sigma-Aldrich (St. Louis, MO). Y-27632 and N-[N-(3,5-Difluorophenacetyl)-L-alanyl]-S-phenylglycine t-butyl ester (DAPT) was from ApexBio Technology (Houston, TX). Red alkaline phosphatase substrate kit was obtained from Vector Labs (Burlingame, CA). Rabbit $\alpha$-Muc2, ZO-1, and integrin $\beta 4$ were obtained from Santa Cruz Biotechnology (Dallas, TX). Donkey serum and donkey anti-rabbit or mouse IgG conjugated with Alexa Fluor 488 were from Jackson Immunoresearch (West Grove, PA). Ko143 was purchased from Cayman Chemical (Ann Arbor, MI). All other reagents were from Thermo Fisher Scientific (Waltham, MA). 


\section{Cell culture media composition}

Expansion media (EM) for cell culture contained advanced DMEM/F12 medium, L-WRN conditioned medium, HEPES (10 mM, pH 7.5), EGF (50 ng/mL), $N$-acetyl cysteine $(1.25 \mathrm{mM})$, B27 $(1 \times)$, GlutaMAX $(2 \mathrm{mM})$, prostaglandin E2 $(10 \mathrm{nM})$, nicotinamide $(10 \mathrm{mM})$, gastrin $(10 \mathrm{nM})$, SB202190 $(3 \mu \mathrm{M})$, penicillin (100 unit $/ \mathrm{mL})$, streptomycin $(100 \mu \mathrm{g} / \mathrm{mL})$, primocin $(100 \mu \mathrm{g} / \mathrm{mL})$, and Y-27632 ROCK inhibitor $(10 \mu \mathrm{M})$. EM lacking Y-27632 ROCK inhibitor was used after the initial $48 \mathrm{~h}$ of culture. L-WRN conditioned medium was prepared by culture of L-WRN cells (ATCC \#CRL-3276) as previously described [68]. This cell line secretes Wnt-3A, R-spondin 3 , and noggin into the medium which was harvested and used a source of growth factors for culture of the small intestinal epithelial cells. Wnt-3A, R-spondin 3, and noggin were used at concentrations of 45,25 , and $25 \mathrm{ng} / \mathrm{mL}$, respectively, to culture the epithelial cells [23]. Differentiation media (DM) contained DMEM/F12 medium, HEPES (10 mM, pH 7.5), GlutaMAX $(2 \mathrm{mM})$, primocin $(100 \mu \mathrm{g} / \mathrm{mL}), N$-acetyl cysteine $(1.25$ $\mathrm{mM})$, EGF $(50 \mathrm{ng} / \mathrm{mL})$, DAPT $(20 \mathrm{ng} / \mathrm{mL})$, and A83-01 (500 ng/mL).

\section{Preparation of a gradient cross-linked scaffold on a porous membrane for cell culture}

A gradient cross-linked scaffold on a porous membrane was prepared according to a published protocol [25]. Briefly, neutralized collagen mixture $(200 \mu \mathrm{L}, 1 \mathrm{mg} / \mathrm{mL}$ rat tail, Type 1) was added to the upper reservoir of a Transwell insert (BD Falcon \#353180, PET membrane, $0.9 \mathrm{~cm}^{2}$ cell culture area, $1.6 \times 10^{6}$ pores $\left./ \mathrm{cm}^{2}\right)$, and then incubated at $37^{\circ} \mathrm{C}$ for $1 \mathrm{~h}$. Following incubation, phosphate buffered saline (PBS, $1 \mathrm{~mL}$ ) was added to the upper and lower reservoir of each Transwell. The Transwell inserts were placed at $4{ }^{\circ} \mathrm{C}$ for $30 \mathrm{~min}$. The PBS in the lower reservoir was replaced with 1-ethyl-3-(3-dimethylaminopropyl) carbodiimide hydrochloride (EDC, $353 \mathrm{mM}$ ) and $N$-hydroxysuccinimide (NHS, $88 \mathrm{mM}$ ) in 2-morpholinoethanesulfonic acid (MES, pH 5.5) to form a gradient of cross-linked collagen along the depth of the scaffold as described previously [25]. The crosslinking ensures the long-term mechanical integrity of scaffolds without cell-induced contraction. The inserts and plates were maintained at $4{ }^{\circ} \mathrm{C}$ for $40 \mathrm{~min}$. The Transwells were removed from the culture plate and immediately placed in deionized water for $24 \mathrm{~h}$. The inserts were then sterilized with $75 \%$ ethanol, rinsed with PBS $\times$ 3 , and stored in PBS at $4{ }^{\circ} \mathrm{C}$ until use.

\section{Preparation of a conventional scaffold on a porous membrane for cell culture}

A conventional scaffold on a porous membrane was prepared by following the manufacturer's protocol (Corning, Corning, NY). Briefly, rat tail collagen $(100 \mu \mathrm{L}, 0.1$ $\mathrm{mg} / \mathrm{mL}$ ) was diluted in ethanol $(70 \%)$ and the mixture was added to the upper reservoir of a Transwell cassette (Corning Life Sciences \#3401, $1.12 \mathrm{~cm}^{2}$ cell culture area, $1.6 \times 10^{8}$ pores $/ \mathrm{cm}^{2}$ ) to form a thin collagen film on the membrane. The Transwell inserts and plates were dried inside a laminar flow hood for $3 \mathrm{~h}$ and sterilized under UV light for $1 \mathrm{~h}$. After sterilization, the upper reservoir and lower reservoir of the Transwells were immediately coated with human collagen $(1 \mathrm{~mL}, 0.01 \mathrm{mg} / \mathrm{mL}$ solution) in sterile PBS. The plates were placed in $37^{\circ} \mathrm{C}$ for $24 \mathrm{~h}$. All liquid was then aspirated from the cassette, the upper and lower reservoirs of the Transwell were washed with $\mathrm{PBS} \times 3$, and the cells were plated immediately afterwards.

\section{Primary human small intestine monolayer cell culture}

Human small intestinal (jejunum) were obtained from a gastric by-pass procedure at UNC Hospitals with patient consent under an approved protocol (UNC IRB \#14-2013). This tissue was acquired from a single donor and used for all experiments in this work. Multiple technical replicates $(n \geq 3)$ were used in all experiments. Crypts/villi were isolated from the tissue following a previously published protocol [23, 24]. Briefly, the tissue was cut longitudinally to expose the luminal and basal sides of the tissue incubated with ethylenediaminetetraacetic acid (EDTA, $2 \mathrm{mM}$ ) and dithiothreitol (DTT, $0.5 \mathrm{mM})$ in buffer $(5.6 \mathrm{mM}$

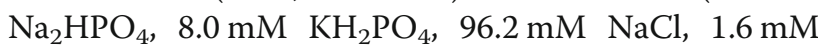
$\mathrm{KCl}, 43.4 \mathrm{mM}$ sucrose, $54.9 \mathrm{mM}$ D-sorbitol, $\mathrm{pH} 7.4$ ) for $90 \mathrm{~min}$ at $25^{\circ} \mathrm{C}$. The crypts/villi were dissociated by vigorous shaking and then collected by centrifugation. The supernatant was removed and replaced with EM. The crypts/villi in EM were plated on a thick non-cross-linked collagen hydrogel $(1 \mathrm{mg} / \mathrm{mL}$, rat tail, $\mathrm{pH}$ 7.4) on a polystyrene tissue culture plate as described previously $[23,24]$. After 5 days, the cells were passaged as previously described [24]. Briefly, the cells along with the collagen hydrogel were removed from the plate surface using a $1000 \mu \mathrm{L}$ pipette tip and transferred into a $15 \mathrm{~mL}$ conical tube containing EM $(1 \mathrm{~mL})$ and $500 \mathrm{U} / \mathrm{mL}$ of Type IV collagenase. The hydrogel with attached cells was fragmented by repeated pipetting using a $1000 \mu \mathrm{L}$ pipette tip and then incubated at $25^{\circ} \mathrm{C}$ for $10 \mathrm{~min}$. This suspension was centrifuged at $600 \times \mathrm{g}$ for $1 \mathrm{~min}$ and the pellet was washed with PBS $(5 \mathrm{~mL})$. The mixture was then re-centrifuged at $600 \times \mathrm{g}$ for $1 \mathrm{~min}$. The pellet was incubated with EDTA $(0.5 \mathrm{mM})$ and Y-27632 $(10 \mu \mathrm{M})$ in PBS at $37^{\circ} \mathrm{C}$ for $10 \mathrm{~min}$. The monolayers were defragmented by repetitive pipetting up/down by a $200 \mu \mathrm{L}$ pipette tip 60 times. The cells were re-suspended in EM and expanded until P5. After P5, the cells were plated on either the gradient cross-linked scaffold or 
conventional scaffold at a cell density of $1.6 \times 10^{5}$ cells $\mathrm{cm}^{-2}$ as described above or stored in liquid nitrogen. If the cells were plated on the gradient cross-linked scaffold or conventional scaffold, the top (luminal) and bottom (basal) compartments of the Transwell cassette contained 1 and $2 \mathrm{~mL}$ of EM, respectively. The height of media fluid in the gradient cross-linked scaffold is $9 \mathrm{~mm}$, and the height of media fluid in the conventional scaffold is $10 \mathrm{~mm}$. After $48 \mathrm{~h}$ of culture, EM without Y-27632 was placed in both cassette compartments (luminal and basal). The EM was replenished every $48 \mathrm{~h}$ for 5 days followed by addition of DM (in place of EM) on day 5. The DM was changed every $24 \mathrm{~h}$ until the monolayers were utilized for experiments. Cells were maintained at $37^{\circ}$ $\mathrm{C}$ in $5 \% \mathrm{CO}_{2}$ incubator. If cells were stored in liquid nitrogen, $1 \mathrm{M}$ cells were snap frozen at P5 in a solution $(1 \mathrm{~mL})$ containing 50\% EM, 40\% FBS, and 10\% DMSO in cryogenic storage vials (Thermo Fisher Scientific, Waltham, MA). Cells were karyotyped (KaryoLogic, Inc., Morrisville, NC) at passage number P15. Twenty cells from each sample $(n=3)$ were analyzed to confirm that the cells possessed a normal human karyotype (Additional file 1: Figure S4). Cells were never used beyond P15.

\section{Stiffness measurements}

The stiffness of the gradient cross-linked and conventional scaffolds were measured in PBS using atomic force microscopy (AFM, Asylum Research MFP3D) as previously described [25]. Prior to AFM analysis, the scaffolds were cut and removed while remaining attached to the permeable membrane, placed on a microscope glass slide and secured with an O-ring made from polydimethylsiloxane (Dow Corning, Midland, MI). A $2.25 \mu \mathrm{m}$ polystyrene spherical bead mounted on a 30 $\mathrm{pN} / \mathrm{nm}$ silicon nitride cantilever (Novascan Technologies, Inc., Ames, IA) was used to apply a force (100$1000 \mathrm{pN}$ ) perpendicularly to the scaffold surfaces. The cantilever's displacement in response to the applied force was recorded. For both scaffold systems, force vs. displacement curves were determined $\geq 5$ different positions across the surface with 5 measurements taken at each position. A thermal tune method was used before measuring the stiffness of each scaffold surface to determine the spring constant of each cantilever (total average spring constant of 2 cantilevers: $31.99 \pm 4.73 \mathrm{pN} / \mathrm{nm}$ ). Stiffness was determined by using the Hertz model to fit force vs. indentation curves [69].

\section{Evaluation of small intestinal epithelial monolayer integrity}

Monolayer integrity was evaluated by TEER and the permeability to fluorescein-dextran M.W. $70 \mathrm{kDA}$ and
Lucifer yellow (LY) M.W. $442.2 \mathrm{~g} / \mathrm{mol}$. Neither LY nor fluorescein-dextran are transported by the intestinal epithelium $[25,54]$. The TEER was measured using an EVOM ${ }^{2}$ epithelial Volt/Ohm meter (World Precision Instruments, Sarasota, FL). The raw resistance measurements of the monolayers were subtracted from that of the average resistance $(n=3)$ of the collagen layer without cells and normalized by multiplying the cell culture area of the well to provide a TEER in units of $\Omega \mathrm{cm}^{2}$ [48]. The average TEER $(n=3)$ with a single standard deviation (SD) is shown (average \pm SD). The permeability of LY $(500 \mu \mathrm{M}$ in DM, $n=3)$ and fluorescein-dextran $(1 \mathrm{mg} / \mathrm{mL}$ in $\mathrm{DM}, n=3)$ was determined by adding the compound to the luminal side of the monolayer and collecting samples from the basal side after $3 \mathrm{~h}$. The amount of LY (ex: $428 \mathrm{~nm}$, em: $520 \mathrm{~nm}$ ) and fluorescein-dextran (ex: $490 \mathrm{~nm}$, em: $520 \mathrm{~nm}$ ) in the basal side was determined by measuring their fluorescence in a microplate reader (Spectramax M5, Molecular Devices Corporation, San Jose, CA).

The luminal-to-basal apparent permeability $\left(\mathrm{P}_{\mathrm{app}}\right)$ were calculated according to the following equation: $\mathrm{P}_{\text {app }}=\left(\mathrm{V} /\left(\mathrm{A} \times \mathrm{C}_{\mathrm{i}}\right)\right) \times\left(\mathrm{C}_{\mathrm{f}} / \mathrm{T}\right)$ where $\mathrm{V}$ is the volume of the basal chamber $(\mathrm{mL}), \mathrm{A}$ is the area of epithelial layer $\left(\mathrm{cm}^{2}\right), C_{i}$ is the initial concentration of the molecule $(\mu \mathrm{M}), \mathrm{C}_{\mathrm{f}}$ is the final concentration of the drug $(\mu \mathrm{M})$, and $\mathrm{T}$ is the assay time (s) [70]. The average $\mathrm{P}_{\mathrm{app}}$ with a single standard deviation is shown (average $\pm \mathrm{SD}$ ).

\section{EdU, ALP, and MUC2 fluorescence stains and quantification}

The small intestine monolayers $(n=3)$ were stained at days 5 and 10 to evaluate cell proliferation and differentiation over time. A 5-ethynyl2-deoxyuridine (EdU) stain was used to mark cells in $S$ phase of the cell cycle. The cells were incubated with EdU $(10 \mu \mathrm{mol} / \mathrm{L})$ in EM or DM (day 5, 10 respectively) at $37^{\circ} \mathrm{C}$ for $6 \mathrm{~h}$. Then, the cells were stained with a Click-iT EdU Alexa Fluor 647 imaging kit according to the manufacturer's directions (Thermo Fisher, Waltham, MA). Enterocyte presence was evaluated by assessing alkaline phosphatase (ALP) activity. The cells were washed with $\mathrm{PBS} \times 3$, incubated for $30 \mathrm{~min}$ at $37^{\circ} \mathrm{C}$ with ALP substrate (Vector red alkaline phosphatase substrate kit; Vector Laboratories, Burlington, CA $)$ in tris buffer $(0.15 \mathrm{~mol} / \mathrm{L}, \mathrm{pH} 8.4)$ for 30 $\mathrm{min}$, and then the monolayers were fixed in paraformaldehyde (4\%) for $15 \mathrm{~min}$. The fixed cells were analyzed for the presence of mucin-2 (Muc2) by immunostaining with a rabbit anti-mucin 2 primary antibody $(\alpha-$ muc2, 1:200, Santa Cruz Biotechnology, Dallas, TX, \#sc-15,334) followed by an Alexa Fluor $488 \alpha$-rabbit secondary antibody (1:500, Jackson Immunoresearch, West Grove, PA, \# 711-545-152). DNA was stained by incubating the cells with Hoechst $33342(2 \mu \mathrm{g} / \mathrm{mL}$, Sigma Aldrich, St. Louis, MO, \#B2261) for $15 \mathrm{~min}$ at $25^{\circ} \mathrm{C}$. 
The monolayers were imaged using a Nikon Eclipse TE300 inverted epifluorescence microscope. Images were acquired with a $10 \times$ objective $($ N.A. $=0.3)$. S-phase cells stained with the Click-iT EdU stain were imaged using a CY5 filter (excitation filter 604-644 nm, emission 672$712 \mathrm{~nm}$ ). The ALP stain was imaged with a Texas Red filter (excitation filter $542-582 \mathrm{~nm}$, emission 604-644 nm). Muc2 immunofluorescence was visualized with a fluorescein filter (excitation filter 450-490 nm, emission $520 \mathrm{~nm}$ long pass). DNA was stained with Hoechst 33342 were analyzed using a DAPI filter (excitation filter 352-402 nm, emission $417-477 \mathrm{~nm}$ ). Images were empirically thresholded using Image J (https://imagej.nih.gov/ij/). The percent surface area of each image displaying supra-threshold fluorescence from the EdU, ALP or Muc2 stains was measured. These areas were then normalized by dividing by the area of the Hoechst fluorescence (DNA stain) resulting in a number that expresses the percentage of the monolayer area positive for the EdU-incorporation, ALP activity, or Muc2 protein. Five different locations in the same monolayer were used to generate the image data and this experiment was repeated $(n=3)$. The average with a single standard deviation is shown (average $\pm \mathrm{SD}$ ).

\section{Other fluorescent staining}

The monolayers were also stained for expression of $\beta$-catenin, filamentous actin (F-actin), integrin $\beta 4$, and $\mathrm{ZO}-1$. For all antibodies, except ZO-1, the cells were first fixed with paraformaldehyde (4\%) for $15 \mathrm{~min}$ and treated with $0.5 \%$ triton $\mathrm{X}-100$ for $20 \mathrm{~min}$ at $37^{\circ} \mathrm{C}$ to facilitate diffusion of the labeling reagents into the cells. For ZO-1, the cells were fixed with methanol $\left(4^{\circ} \mathrm{C}\right)$ and incubated at $-20{ }^{\circ} \mathrm{C}$ for $20 \mathrm{~min}$. The cells were blocked with $10 \%$ donkey serum (Jackson Immunoresearch, West Grove, PA, \# 017-000-121) for $1 \mathrm{~h}$ at $20^{\circ} \mathrm{C}$. The cells were then incubated in primary antibody at $4{ }^{\circ} \mathrm{C}$ for $24 \mathrm{~h}$. After $24 \mathrm{~h}$, the samples were stained with a secondary antibody for $45 \mathrm{~min}$ at $20^{\circ} \mathrm{C}$. Primary antibodies used were rabbit anti-integrin $\beta 4$ (1:200, Santa Cruz sc-9090; Santa Cruz Technology, Santa Cruz, CA), rabbit anti-ZO-1 (1:100, Proteintech 21,773-1-AP; Wuhan, China), and rabbit anti- $\beta$-catenin (1:200, Santa Cruz sc-7199, Santa Cruz Technology, Santa Cruz, CA). The secondary antibodies were donkey anti-rabbit immunoglobulin G conjugated with either Alexa Fluor 488 or 594 (1:500, Jackson Immunoresearch 711-545-152 or 711-585-152, West Grove, PA) or Alexa Fluor 488 phalloidin stained F-actin (Thermo Fisher A12379). When staining cross-sections of the monolayer for integrin $\beta 4$ and actin, the samples were fixed in paraformaldehyde (4\%) for $15 \mathrm{~min}$, rinsed with $\mathrm{PBS}$, and incubated overnight in $30 \%$ sucrose at $4{ }^{\circ} \mathrm{C}$. The monolayer was then submerged in a cryo-embedding medium (OCT). The frozen tissue block was sectioned into $10-\mu \mathrm{m}$ thick films with a cryostat.

To measure the thickness of collagen in the gradient cross-linked scaffold and conventional scaffold, collagen was plated in each culture system as previously described in this manuscript. Collagen was incubated with NHS-Fluorescein in PBS $(0.25 \mu \mathrm{g} / \mathrm{mL}$, Thermo Fisher, Waltham, MA, \#46410) at $25^{\circ} \mathrm{C}$ for $24 \mathrm{~h}$, and immediately placed in deionized water for $24 \mathrm{~h}$. Images were immediately acquired by a confocal laser scanning microscope (Fluoview FV3000; Olympus, Waltham, MA) and visualized with a fluorescein filter (excitation filter 467-498 nm, emission 505-548). Images shown in Fig. 1a were acquired with a $20 \times$ objective (N.A. $=0.45$ ). The collagen layer in the conventional scaffold was not visible using a 30x objective (N.A. $=1.05$ ) which has a Z-resolution of $900 \mathrm{~nm}$ [71].

\section{Electron microscopy}

Scanning electron microscopy (SEM) was utilized to evaluate the presence of microvilli. The monolayers were fixed with paraformaldehyde (4\%) for $15 \mathrm{~min}$. Then the monolayers were incubated in deionized water for $24 \mathrm{~h}$. After 24 $\mathrm{h}$, the monolayers were placed into 25,50 , and $75 \%$ ethanol sequentially for $1 \mathrm{~h}$. The monolayers were placed in a critical point dryer (PVT-3, Tousimis Semidri, Rockville, MD) to dehydrate the samples. The monolayers were then coated with metal (10 nm gold; Cresington Scientific Instruments) and imaged by a scanning electron microscope (FEI Quanta 200 ESEM, FEI Company, Hillsboro, OR).

\section{Proteomic analysis}

QTAP nanoLC-MS/MS methods previously published were used to quantify protein expression of drug transporters, NaK ATPase, and GGTP in the monolayers and fresh crypts/villi [72, 73]. The monolayer samples were prepared from 10 million cells that were pooled and homogenized in hypotonic buffer containing $10 \mathrm{mM}$ tris $\mathrm{HCl}$ (pH 7.4), 10 $\mathrm{mM} \mathrm{NaCl}, 1.5 \mathrm{mM} \mathrm{MgCl}_{2}$. The samples were centrifuged $\left(10,000 \mathrm{rcf}, 4^{\circ} \mathrm{C}\right)$ and the protein in the supernatant was pelleted by ultracentrifugation $\left(100,000 \mathrm{rcf}, 4^{\circ} \mathrm{C}\right)$. The resulting membrane fraction was re-suspended in fresh PBS for analysis. Prior to nanoLC-MS/MS analysis, a stable isotope-labeled proteotypic tryptic peptide standard of known concentration was added to the membrane fraction samples. Absolute quantification was determined from the ratio of two SRM peak area signals of the analyte summed to two corresponding signals of the stable isotope-labeled peptide standard summed, equality of response between the analyte (unlabeled) and labeled peptides being assumed.

\section{Functional transport assays}

All transport assays were performed by adding LY $(500 \mu \mathrm{m})$ and the drug to the luminal or basal reservoirs 
of the monolayer $(n=3)$. Samples were collected after 3 h. LY was added to ensure that monolayer integrity remained intact throughout the assay. Additionally, TEER was measured before and after the assay to further verify that monolayer integrity remained constant throughout the assay. Monolayers with a TEER $>90 \Omega$ $\mathrm{cm}^{2}$ or $300 \Omega \mathrm{cm}^{2}$ were used for the gradient cross-linked scaffold and conventional scaffold, respectively. These values were established based on the TEER at which the monolayer was impermeable to LY. For atenolol and propranolol, the compounds were added to the luminal compartment, and fluid was collected from the basal compartment. Bidirectional transport of digoxin and prazosin in the presence and absence of a known selective inhibitor was evaluated. Zosuquidar and Ko143 were added to inhibit digoxin transport and prazosin transport, respectively, $2.5 \mathrm{~h}$ after addition of the substrate. Samples were collected $30 \mathrm{~min}$ after inhibitor addition for a totally assay time of $3 \mathrm{~h}$.

The concentration of the drug in the collected sample was determined using HPLC-triple quadrupole mass spectrometry (LC-MS/MS, PE Sciex API 3000, AB Sciex) with multiple reaction monitoring (MRM). A C-18 analytical column with a linear gradient from $100 \%$ water with $1 \%$ formic acid to $80 \%$ acetonitrile with $1 \%$ formic acid over 8 $\min (0.3 \mathrm{~mL} / \mathrm{min})$ was used for the separation. Metoprolol was used as an internal standard for atenolol and propranolol samples. Digitoxin was used as an internal standard for digoxin samples. Doxasozin was used an internal standard for prazosin samples. All internal standards were added to samples just prior to LC-MS/MS analysis. Eluted species were subjected to electrospray ionization (positive mode) and transitions of 267.2/190 (m/z of precursor ion/product ion) for atenolol, 260.2/116.1 for propranolol, 268.2/116.1 for metoprolol, 798.5/651.5 for digoxin, 782.5/635.5 for digitoxin, 384.3/247.2 for prazosin, and $452.3 / 344.3$ for doxazosin were identified [56, 74, 75]. Sample concentrations were quantified using the standard curve and normalized to the signal of the appropriate internal standard. The drug apparent permeability was calculated according to the following equation: $\mathrm{P}_{\mathrm{app}}=\left(\mathrm{V} /\left(\mathrm{A} \times \mathrm{C}_{\mathrm{i}}\right)\right) \times\left(\mathrm{C}_{\mathrm{f}} / \mathrm{T}\right)$ where $\mathrm{V}$ is the volume of the basal chamber $(\mathrm{mL}), \mathrm{A}$ is the area of epithelial layer $\left(\mathrm{cm}^{2}\right), \mathrm{C}_{\mathrm{i}}$ is the initial concentration of the molecule $(\mathrm{nM}), \mathrm{C}_{\mathrm{f}}$ is the final concentration of the drug, and $\mathrm{T}$ is the assay time (s) [70]. The average $\mathrm{P}_{\text {app }}$ with a single standard deviation is shown (average $\pm \mathrm{SD}$ ). The efflux ratio was calculated according to the following equation: Efflux Ratio $=\mathrm{P}_{\text {app }}(\mathrm{B}-\mathrm{L}) / \mathrm{P}_{\text {app }}(\mathrm{L}-\mathrm{B})[16]$.

\section{Statistical analysis}

Statistical analysis of ALP, Muc2, and Edu quantification as well as transporter proteomic analysis and the functional transport assays was performed as described above.
For all permeability assays (LY, fluorescein-dextran, atenolol, propranolol, digoxin, prazosin), statistical analysis was performed with Tukey's honest significant difference procedure conducted at the $5 \%$ significance level. In all figures '*' denotes $p<0.05$ and '**' $p<0.005$. The average with a single standard deviation (SD) is shown (average \pm $\mathrm{SD})$. All experiments were performed in triplicate unless specified otherwise.

\section{Additional file}

\begin{abstract}
Additional file 1: Figure S1. Day 5 Edu Staining of intestinal epithelia cells in expansion medium (EM). Fluorescence images of the monolayers at day 5 stained for EdU (green), and nuclei (blue). Scale bar $=100 \mu \mathrm{m}$. Figure S2. QTAP SRM quantification of selected transporters. Protein concentration $(\mathrm{pmol} / \mathrm{mg})$ of selected transporters of the monolayers in the thick collagen scaffold and thin layer collagen over the porous membrane at day 10 compared to that of fresh crypts/villi. Figure S3. Oxygen saturation evaluation. COMSOL Multiphysics simulations of oxygen saturation for (A) gradient cross-linked scaffold and (B) conventional scaffold. The oxygen saturation is shown $3 \mathrm{~h}$ after the start of a transport assay i.e. medium exchange. In the gradient cross-linked scaffold and conventional scaffold, the oxygen saturation in the luminal reservoir $1 \mathrm{~mm}$ above the cells was nearly identical for the two culture formats $(10.1 \%$ and $9.5 \%$ for the gradient cross-linked and conventional formats, respectively). Figure S4. Karyotyping results. Cytogenetic analysis showing a normal human female karyotype at P15. Table S1. Detailed list of the differences between the gradient cross-linked scaffold system and conventional scaffold system. Table S2. Human transporter proteotypic heavy labeled tryptic peptides standards (purchased from Theracode JPT Inc., Acton, MA) and MRMs acquired. Cterminus $\mathrm{R}$ and $\mathrm{K}$ amino acids are ${ }^{13} \mathrm{C}$ and ${ }^{15} \mathrm{~N}$ heavy labeled (shown in bold). The mass differences between labeled (shown) and unlabeled (not shown) $\mathrm{R}$ and $\mathrm{K}$ are 10 and 8 respectively. Mass shift for transition ions, between labeled and unlabeled, also depends on the charge state. The product ion for most heavy labeled peptide MRMs contains the heavy label. Peptide selection had been based on in silico assessment, crude peptide evaluation and available literature. Where necessary, peptides used when reporting concentrations are marked with $\bullet$. (DOCX 368 kb)
\end{abstract}

\section{Acknowledgements}

The authors thank Bailey Zwarcyz for procuring the human tissue, Mark Reed for immunostaining and cryosectioning, Johanna Dutton for SEM training, Matt DiSalvo for confocal microscopy training, and Joseph Hwang for scaffold preparation. This work was performed in part at the Chapel Hill Analytical and Nanofabrication Laboratory, CHANL, a member of the North Carolina Research Triangle Nanotechnology Network, RTNN, which is supported by the National Science Foundation, Grant ECCS-1542015, as part of the National Nanotechnology Coordinated Infrastructure, $\mathrm{NNCl}$. This work was also performed in part at the UNC Chemistry mass spectrometry core laboratory.

\section{Funding}

Research reported in this publication was supported by the National Institutes of Health under award number R01DK109559.

\section{Availability of data and materials}

The datasets during and/or analysed during the current study available from the corresponding author on reasonable request.

\section{Supporting information}

Day 5 Edu staining of the intestinal epithelial cells in EM on both culture platforms, QTAP SRM quantification of selected transporters, COMSOL simulations of the oxygen concentration near the cells on the two platforms, Karyotyping results, Detailed list of the differences between the gradient cross-linked scaffold system and conventional scaffold system, and the peptide markers of all transporter proteins evaluated in the monolayers and crypts/villi via QTAP SRM can be found in the supporting information. 


\section{Authors' contributions}

JS., DB., and JF. performed and designed experiments. JS., DB., YW., JF., PS., and NA. were involved in design, planning and supervising the work. JS., DB. YW., JF., PA., and PS. processed the experimental data and performed analysis. JS., CS., NA. wrote the manuscript. All authors reviewed and approved the manuscript.

\section{Ethics approval and consent to participate}

Research involving human material was performed in accordance with the Declaration of Helsinki and approved by the Institutional Review Board and the Office of Human Research Ethics at the University of North Carolina. Human small intestinal (jejunum) were obtained from a gastric by-pass procedure at UNC Hospitals with patient consent under an approved protocol (UNC IRB \#14-2013).

\section{Consent for publication}

The manuscript contains no details, images, or videos relating to an individual person so that this section is not applicable.

\section{Competing interests}

N.L.A., C.E.S., Y.W. have a financial interest in Altis Biosystems, Inc. The remaining authors disclose no conflicts.

\section{Publisher's Note}

Springer Nature remains neutral with regard to jurisdictional claims in published maps and institutional affiliations.

\section{Author details}

'Department of Chemistry, University of North Carolina, Chapel Hill, NC 27599, USA. ${ }^{2}$ Joint Department of Biomedical Engineering, University of North Carolina and North Carolina State University, Raleigh, NC 27599, USA. ${ }^{3}$ Division of Pharmacoengineering and Molecular Pharmaceutics, Eshelman School of Pharmacy, University of North Carolina, Chapel Hill, NC 27599, USA.

Received: 4 January 2019 Accepted: 8 April 2019

Published online: 27 April 2019

\section{References}

1. Kiela PR, Ghishan FK. Best Practice \& Research Clinical Gastroenterology Physiology of intestinal absorption and secretion. Best Pract Res Clin Gastroenterol. 2016;30(2):145-59.

2. Pang KS. Modeling of intestinal drug absorption: Roles of Transporters and Metabolic Enzymes (for the Gillette Review Series). Drug Metab Dispos. 2003:31(12):1507-1519.

3. Crawley SW, Mooseker MS, Tyska MJ. Shaping the intestinal brush border. Cell Biol. 2014:207(4):441-51.

4. Lodish H, Berk A, Zipursky S. Transport across Epithelia. In: Molecular Cell Biology [Internet]. 4th ed. New York: W. H. Freeman; 2000. Available from: https://www.ncbi.nlm.nih.gov/books/NBK21502/

5. Lin L, Yee SW, Kim RB, Giacomini KM. SLC transporters as therapeutic targets: emerging opportunities. Nat Rev Drug Discov. 2015;14(8):543-60.

6. Choi C. ABC transporters as multidrug resistance mechanisms and the development of chemosensitizers for their reversal. Cancer Cell Int. 2005; 5(30):5-30.

7. Estudante $M$, Morais JG, Soveral G, Benet LZ. Intestinal drug transporters: an overview. Adv Drug Deliv Rev. 2013;65(10):1340-56.

8. Müller J, Lips KS, Metzner L, Neubert RHH, Koepsell H, Brandsch M. Drug specificity and intestinal membrane localization of human organic cation transporters (OCT). Biochem Pharmacol. 2005:70(12):1851-60.

9. Gal-Garber O, Mabjeesh SJ, Sklan D, Uni Z. Nutrient transport in the small intestine: $\mathrm{Na}+\mathrm{K}+$-ATPase expression and activity in the small intestine of the chicken as influenced by dietary sodium. Poult Sci. 2003;82(7):1127-33.

10. Cohen MI, Gartner LM, Blumenfeld OO, Arias IM. Gamma glutamyl transpeptidase: measurement and development in Guinea pig small intestine. Pediatr Res. 1969;3(1):5-10.

11. Rana SV, Gupta D, Katyal R, Singh K. Mild-to-moderate malnutrition alters and Glycine uptake in small intestinal brush-border vesicles of rhesus monkeys. Ann Nutr Metab. 2001;45(4):143-7.

12. Larregieu $C A$, Benet $L Z$. Drug discovery and regulatory considerations for improving In silico and In vitro predictions that use Caco-2 as a surrogate for human intestinal permeability measurements. AAPS J. 2013;15(2):483-97.
13. Billat P-A, Roger E, Faure S, Lagarce F. Models for drug absorption from the small intestine: where are we and where are we going? Drug Discov Today. 2017;22(5):761-75.

14. Vaessen S, van Lipzig M, Pieters R, Krul C, Wortelboer H, van de Steeg E. Regional expression levels of drug transporters and metabolizing enzymes along the pig and human intestinal tract and comparison with Caco-2 cells. Drug Metab Dispos. 2017;45(4):353-60.

15. Ayehunie $S$, Landry T, Stevens $Z$, Armento A, Hayden P, Primary KMH. Cellbased Organotypic microtissues for modeling small intestinal drug absorption. Pharm Res. 2018;35(4):72.

16. Madden LR, Nguyen TV, Garcia-Mojica S, Shah V, Le AV, Peier A, et al. Bioprinted 3D Primary human intestinal tissues model aspects of native physiology and ADME/Tox functions. iScience. 2018;2:156-67.

17. Kasendra M, Tovaglieri A, Sontheimer-Phelps A, Jalili-Firoozinezhad S, Bein A, Chalkiadaki $A$, et al. Development of a primary human small intestine-on-aChip using biopsy-derived organoids. Sci Rep. 2018;8(1):1-14.

18. Schweinlin M, Wilhelm S, Schwedhelm I, Hansmann J, Rietscher R, Jurowich $C$, et al. Development of an advanced Primary human In vitro model of the small intestine. Tissue Eng Part C Methods. 2016;22(9):873-83.

19. Sato $T$, Stange DE, Ferrante $M, V$ ries RGJ, van Es JH, van den Brink $S$, et al. Long-term expansion of epithelial organoids from human Colon, adenoma, adenocarcinoma, and Barrett's epithelium. Gastroenterology. 2011;141(5): 1762-72.

20. VanDussen KL, Marinshaw JM, Shaikh N, Miyoshi H, Moon C, Tarr Pl, et al. Development of an enhanced human gastrointestinal epithelial culture system to facilitate patient-based assays. Gut. 2015;64(6):911-20.

21. Meran L, Baulies A, Li VL. Intestinal stem cell niche: the extracellular matrix and cellular components. Stem Cells Int. 2017;17:1-11.

22. Wang Y, Kim R, Hinman SS, Zwarycz B, Magness ST, Allbritton NL. Bioengineered systems and designer matrices that recapitulate the intestinal stem cell niche. CMGH. 2018;5(3):440-53.

23. Wang Y, DiSalvo M, Gunasekara DB, Dutton J, Proctor A, Lebhar MS, et al. Self-renewing monolayer of Primary colonic or rectal epithelial cells. CMGH. 2017:4(1):165-82.

24. Bhatt AP, Gunasekara DB, Speer J, Reed MI, Peña AN, Midkiff BR, et al. Nonsteroidal anti-inflammatory drug-induced leaky gut modeled using polarized monolayers of Primary human intestinal epithelial cells. ACS Infect Dis. 2018:4(1):46-52.

25. Gunasekara DB, Speer J, Wang Y, Nguyen DL, Reed MI, Smiddy NM, et al. A monolayer of Primary colonic epithelium generated on a scaffold with a gradient of stiffness for drug transport studies. Anal Chem. 2018; 90(22):13331-40.

26. Wells RG. The role of matrix stiffness in regulating cell behavior. Hepatology. 2008:47(4):1394-400

27. Xu J, Sun M, Tan $Y$, Wang $H$, Wang $H$, Li $P$, et al. Effect of matrix stiffness on the proliferation and differentiation of umbilical cord mesenchymal stem cells. Differentiation. 2017:96:30-9.

28. Li N, Xie T, Sun Y. Towards organogenesis and morphogenesis in vitro harnessing engineered microenvironment and autonomous behaviors of pluripotent stem cells. Integr Biol. 2018;10(10):574-86.

29. Guilak F, Cohen DM, Estes BT, Gimble JM, Liedtke W, Chen CS. Control of stem cell fate by physical interactions with the extracellular matrix. Cell Stem Cell. 2009:5(1):17-26.

30. Trappmann B, Gautrot JE, Connelly JT, Strange DGT, Li Y, Oyen ML, et al. Extracellular-matrix tethering regulates stem-cell fate. Nat Mater. 2012;11(7): 642-9.

31. Imajo M, Ebisuya M, Nishida E. Dual role of YAP and TAZ in renewal of the intestinal epithelium. Nat Cell Biol. 2015;17(1):7-19.

32. Gjorevski N, Sachs N, Manfrin A, Giger S, Bragina ME, Ordóñez-Morán P, et al. Designer matrices for intestinal stem cell and organoid culture. Nature. 2016:539(7630):560-4.

33. Lu Y, Nakanishi T, Hosomi A, Komori H, Tamai I. In-vitro evidence of enhanced breast cancer resistance protein-mediated intestinal urate secretion by uremic toxins in Caco-2 cells. J Pharm Pharmacol. 2015;67(2):170-7.

34. Bolze $S$, Fardel $\mathrm{O}$. Analysis of drug transporter expression in human intestinal Caco-2 cells by real-time PCR. Fundam Clin Pharmacol. 2007;21(6): 659-63.

35. Pastuła A, Middelhoff M, Brandtner A, Tobiasch M, Höhl B, Nuber AH, et al. Three-dimensional gastrointestinal organoid culture in combination with nerves or fibroblasts: a method to characterize the gastrointestinal stem cell niche. Stem Cells Int. 2016;2016:3710836. 
36. Chen HJ, Miller P, Shuler ML. A pumpless body-on-a-chip model using a primary culture of human intestinal cells and a 3D culture of liver cells. Lab Chip. 2018;18(14):2036-46.

37. Ou G, Baranov V, Lundmark E, Hammarström S, Hammarström ML. Contribution of intestinal epithelial cells to innate immunity of the human gut - studies on polarized monolayers of colon carcinoma cells. Scand J Immunol. 2009;69(2):150-61.

38. Chen T, Hubbard A, Murtazina R, Price J, Yang J, Cha B, et al. Myosin VI mediates the movement of NHE3 down the microvillus in intestinal epithelial cells. J Cell Sci. 2014;127(16):3535-45.

39. Wang L, Murthy SK, Barabino GA, Carrier RL. Synergic effects of crypt-like topography and ECM proteins on intestinal cell behavior in collagen based membranes. Biomaterials. 2010;31(29):7586-98.

40. Stewart DC, Berrie D, Li J, Liu X, Rickerson C, Mkoji D, et al. Quantitative assessment of intestinal stiffness and associations with fibrosis in human inflammatory bowel disease. PLoS One. 2018;13(7):1-16.

41. Jin S, Huantong Y, Krisanarungson P, Haukas A, Ye K. Porous membrane substrates offer better niches to enhance the Wnt signaling and promote human embryonic stem cell growth and differentiation. Tissue Eng Part A. 2012;18(13-14):1419-30.

42. Cao $K$, Wang $Y$, Wang $Y$. Experimental investigation and modeling of the tension behavior of polycarbonate with temperature effects from low to high strain rates. Int J Solids Struct. 2014;51(13):2539-48.

43. Williams JM, Duckworth CA, Burkitt MD, Watson AJM, Campbell BJ, Pritchard DM. Epithelial cell shedding and barrier function: a matter of life and death at the small intestinal villus tip. Vet Pathol. 2015;52(3):445-55.

44. Bjorkman DJ, Allan CH, Hagen SJ, Trier JS. Structural features of absorptive cell and microvillus membrane preparations from rat small intestine. Gastroenterology. 1986;91(6):1401-14

45. Mayhew TM, Middleton C. Crypts, villi and microvilli in the small intestine of the rat. A stereological study of their variability within and between animals. J Anat. 1985:141:1-17.

46. Casteleyn C, Rekecki A, Van Der Aa A, Simoens P, Van Den Broeck W. Surface area assessment of the murine intestinal tract as a prerequisite for oral dose translation from mouse to man. Lab Anim. 2010;44(3):176-83.

47. Calderwood DA, Shattil SJ, Ginsberg MH. Integrins and actin filaments : reciprocal regulation of cell adhesion and signaling. J Biol Chem. 2000; 275(30):22607-10.

48. Chen S, Einspanier R, Schoen J. Transepithelial electrical resistance (TEER): a functional parameter to monitor the quality of oviduct epithelial cells cultured on filter supports. Histochem Cell Biol. 2015;144(5):509-15.

49. Feng $Y$, Sun $X$, Yang $H$, Teitelbaum DH. Dissociation of E-cadherin and $\beta$ -catenin in a mouse model of total parenteral nutrition : a mechanism for the loss of epithelial cell proliferation and villus atrophy. J Physiol. 2009; 587(3):641-54

50. Srinivasan B, Kolli AR, Esch MB, Abaci HE, Shuler ML, Hickman JJ. TEER measurement techniques for In vitro barrier model systems. J Lab Autom. 2015;20(2):107-26.

51. Mukherjee T, Squillantea E, Gillespieb M, Shao J. Transepithelial electrical resistance is not a reliable measurement of the Caco- 2 monolayer integrity in Transwell. Drug Deliv J Deliv Target Ther Agents. 2004:11(1):11-8.

52. Yamaura Y, Chapron BD, Wang Z, Himmelfarb J, Thummel KE. Functional comparison of human colonic carcinoma cell lines and Primary small intestinal epithelial cells for investigations of intestinal drug permeability and first-pass metabolism. Drug Metab Dispos. 2015;25:329-35.

53. Konishi $Y$, Hagiwara K, Shimizu M. Transepithelial transport of fluorescein in Caco-2 cell monolayers and use of such transport in In vitro evaluation of phenolic acid availability. Biosci Biotechnol Biochem. 2002;66(11):2449-57.

54. Hubatsch I, Ragnarsson EGE, Artursson P. Determination of drug permeability and prediction of drug absorption in Caco-2 monolayers. Nat Protoc. 2007;2(9):2111-9

55. Foulke-Abel J, In J, Yin J, Zachos NC, Kovbasnjuk O, Estes MK, et al. Human Enteroids as a model of upper small intestinal ion transport physiology and pathophysiology. Gastroenterology. 2016;150(8):638-49.

56. Saleem K, Ali I, Kulsum U, Aboul-Enein HY. Recent developments in HPLC analysis of beta-blockers in biological samples. J Chromatogr Sci. 2013;51(8):807-18.

57. Chen $X$, Slättengren T, Lange ECM, Smith DE, Hammarlund-Udenaes M. Revisiting atenolol as a low passive permeability marker. Fluids Barriers CNS. 2017;14(1):1-14.

58. Wessler JD, Grip LT, Mendell J, Giugliano RP. The P-glycoprotein transport system and cardiovascular drugs. J Am Coll Cardiol. 2013;61(25):2495-502.
59. Da Silva LC, Da Silva TL, Antunes AH, Rezende KR. A sensitive mediumthroughput method to predict intestinal absorption in humans using rat intestinal tissue segments. J Pharm Sci. 2015;104(9):2807-12.

60. Yamaura Y, Chapron BD, Wang Z, Himmelfarb J, Thummel KE. Functional comparison of human colonic carcinoma cell lines and Primary small intestinal epithelial cells for investigations of intestinal drug permeability and first-pass metabolism. Drug Metab Dispos. 2016;44(3):329-35.

61. Wang XX, Liu GY, Yang YF, Wu XW, Xu W, Yang XW. Intestinal absorption of triterpenoids and flavonoids from Glycyrrhizae radix et rhizoma in the human Caco-2 monolayer cell model. Molecules. 2017;22(10):1627.

62. Nagare N, Damre A, Singh KS, Mallurwar SR, lyer S, Naik A, MC. Determination of site of absorption of propranolol in rat gut using In situ single-pass intestinal perfusion. Indian J Pharm Sci. 2010;72(5):625-9.

63. lqbal J, Hombach J, Matuszczak B, Bernkop-Schnürch A. Design and in vitro evaluation of a novel polymeric P-glycoprotein (P-gp) inhibitor. J Control Release. 2010;147(1):62-9.

64. Takara K, Tsujimoto M, Ohnishi N, Yokoyama T. Digoxin up-regulates MDR1 in human Colon carcinoma Caco-2 cells. Biochem Biophys Res Commun. 2002;292(1):190-4

65. Koola MM, Varghese SP, Fawcett JA. High-dose prazosin for the treatment of post-traumatic stress disorder. Ther Adv Psychopharmacol. 2014;4(1):43-7

66. Zhang D, He K, Herbst JJ, Kolb J, Shou W, Wang L, et al. Characterization of efflux transporters involved in distribution and disposition of apixaban. Drug Metab Dispos. 2013;41(4):827-35.

67. Engler AJ, Sen S, Sweeney HL, Discher DE. Matrix elasticity directs stem cell lineage specification. Cell. 2006;126(4):677-89.

68. Miyoshi H, Stappenbeck TS. In vitro expansion and genetic modification of gastrointestinal stem cells in spheroid culture. Nat Protoc. 2013;8(12):2471-82.

69. Sokolov I. Atomic force microscopy in cancer cell research. Cancer Nanotechnol. 2007;1:1-17.

70. Miyamoto Y, Yuasa H, Iga T, Hanano M. Determination of the membrane permeability coefficient and the reflection coefficient by the twodimensional laminar flow model for intestinal perfusion experiments. BBA Biomembr. 1986;854(2):191-7.

71. Zhang Q, Yang X, Qinglei H, Bai K, Yin F, Li N, et al. High axial resolution imaging system for large volume tissues using combination of inclined selective plane illumination and mechanical sectioning. Biomed Opt Express. 2017;8(12):5767-75.

72. Fallon JK, Neubert H, Hyland R, Goosen TC, Smith PC. Targeted quantitative proteomics for the analysis of 14 UGT1As and -2Bs in human liver using NanoUPLC - MS/MS with selected reaction monitoring. J Proteome Res. 2013;12:4402-13.

73. Fallon JK, Smith PC, Xia CQ, Kim M. Quantification of four efflux drug transporters in liver and kidney across species using targeted quantitative proteomics by isotope dilution NanoLC-MS / MS. Pharm Res. 2016;33(9): 2280-8.

74. Øiestad EL, Johansen U, Opdal MS, Bergan S, Christophersen AS. Determination of digoxin and digitoxin in whole blood. J Anal Toxicol. 2009;33(7):372-8.

75. Erceg $M$, Cindric $M$, Frketic LP, Vertzoni $M$, Cetina-cižmek B, Reppas C. A LC - MS - MS Method for Determination of Low Doxazosin Concentrations in Plasma after Oral Administration to Dogs. J Chromatogr Sci. 2010:48(2):114-9.

Ready to submit your research? Choose BMC and benefit from

- fast, convenient online submission

- thorough peer review by experienced researchers in your field

- rapid publication on acceptance

- support for research data, including large and complex data types

- gold Open Access which fosters wider collaboration and increased citations

- maximum visibility for your research: over $100 \mathrm{M}$ website views per year

At $\mathrm{BMC}$, research is always in progress.

Learn more biomedcentral.com/submissions 